\title{
Oil and stock price returns: Evidence from European industrial sector indices in a time-varying environment
}

\author{
Stavros Degiannakis ${ }^{1}$, George Filis ${ }^{* 2}$ and Christos Floros ${ }^{3,4}$ \\ ${ }^{1}$ Economic Research Department, Bank of Greece, 21 E. Venizelos Avenue, GR10250 \\ Athens, Greece \\ ${ }^{2}$ Department of Accounting, Finance and Economics, Bournemouth University, Bournemouth \\ Business School, The Executive Business Centre, 89 Holdenhurst Road, BH8 8EB \\ Bournemouth, United Kingdom \\ ${ }^{3}$ University of Portsmouth, Department of Economics, Richmond Building, Portland Street, \\ PO1 3DE Portsmouth, United Kingdom \\ ${ }^{4}$ Department of Finance and Insurance, Technological Educational Institute of Crete, \\ GR72100, Greece
}

*Corresponding author: email: gfilis@ bournemouth.ac.uk, tel: 0044 (0) 1202 968739, fax:

$0044(0) 1202968833$

\begin{abstract}
The time-varying correlation between oil prices returns and European industrial sector indices returns, considering the origin of the oil price shock, is investigated. A time-varying multivariate heteroskedastic framework is employed to test the above hypothesis based on data from 10 European sectors. The contemporaneous correlations suggest that the relationship between sector indices and oil prices change over time and they are industry specific. In addition, the supply-side oil price shocks result in low to moderate positive correlation levels, the precautionary demand oil price shocks lead to almost zero correlation levels, whereas the aggregate demand oil price shocks generate significant changes in the correlation levels (either positive or negative). Both the origin of the oil price shock and the type of industry are important determinants of the correlation level between industrial sectors' returns and oil prices. Prominent among the results is the fact that during the financial crisis of 2008 some sectors were providing diversification opportunities to investors dealing with the crude oil market.
\end{abstract}

JEL: C32, C51, G1, Q4.

Keywords: Diag-VECH GARCH, Dynamic correlation, Multivariate Heteroskedastic Framework, Oil Price Returns, Oil Price Shocks, Stock Market Sectors. 


\section{Introduction}

A wealth of literature has investigated the relationship between oil price returns and economic activity since the seminal paper published by Hamilton (1983) ${ }^{1}$. A recent detailed theoretical description of this relationship is given by Iwayemi and Fowowe (2011). Nevertheless, the literature of the relationship between oil prices and stock market developments is still growing ${ }^{2}$. Even more, the findings on the relationship between oil prices and industrial sector indices are scarce. According to Arouri et al. (2012, p.2) "the use of equity sector indices is, in our opinions, advantageous because market aggregation may mask the characteristics of various sectors". Adding to this growing literature, the aim of this study is to examine the effects of the oil price returns on industrial sector indices in Europe, in a time-varying framework. The recent evidence show that the relationship between oil price returns and aggregate stock market returns is indeed time-varying (Saborsky, 2012; Chang et al., 2012; Filis et al., 2011; Bharn and Nikolovann, 2010; Choi and Hammoudeh, 2010; Aloui and Jammazi, 2009). Nevertheless, the focus of this paper is on the industrial sector indices rather than aggregate stock market returns, which was the focus of all aforementioned studies. In addition, it is also evident by the same studies that the unconditional correlations cannot capture the dynamics of the said relationship.

The vast majority of the literature has focused on the effects of oil price changes on stock market returns. The current evidence suggests that oil price changes are associated with fluctuations in stock prices, although the results are mixed. Part of past studies maintain that there is an adverse and asymmetric impact of oil price shocks on the financial markets (see, inter alia, Filis, 2010; Chen, 2009; Miller and Ratti, 2009; Park and Ratti, 2008; Driesprong et al., 2008; Gjerde and Sættem, 1999; Jones and Kaul, 1996). Nonetheless, the effects of oil shocks on stock markets for a specific country can be positive or negative depending on whether the country is a net producer or net consumer of oil resources, see Mohanty et al. (2011). Thus, the negative relationship which was established in the previous studies does not

\footnotetext{
${ }^{1}$ There are two views on the role of oil prices to the economy: (1) the microeconomic view (e.g. effects of oil prices on pricing and production), and (2) the macroeconomic view (impact of oil prices on aggregate demand through, for example, inflation - monetary policy responses), see Segal (2011). Some important studies on the relationship between oil price shocks and economic activity include Baumeister and Peersman (2012), Blanchard and Gali (2007), Hamilton (2008), Hamilton and Herrera (2004), Barsky and Kilian (2004), Brown and Yuncel (2002) and Bernanke et al., (1997). Recent studies include Rahman and Serletis (2010), Tang et al. (2010), Jbir and Zouari-Ghorbel (2009) and Jones et al. (2004).

${ }^{2}$ See, Park and Ratti (2008), Henriques and Sadorsky (2008), Basher and Sadorsky (2006), Huang et al. (2005), Hammoudeh and Huimin (2005), Hammoudeh et al. (2004), Hammoudeh and Aleisa (2004), Sadorsky (2001), Papapetrou (2001), Faff and Brailsford (1999), Huang et al. (1996), Jones and Kaul (1996), Kaneko and Lee (1995), Ferson and Harvey (1994, 1995), Sadorsky (1999), among others.
} 
hold for stock markets operating in oil-exporting countries, but rather a positive relationship exists, as shown by Arouri and Rault (2012) and Bjornland (2009), among others.

There are authors, though, who voice the opinion that there is not any relationship between oil price shocks and stock market returns (Jammazi and Aloui, 2010; Cong et al., 2008; Huang et al., 1996). An extensive recent review on the literature in this research topic can be found in Filis et al. (2011).

Furthermore, Hamilton (2009a,b), Kilian (2008b) and Kilian and Park (2009), opine that different shocks in the crude oil market have different effects on the stock market, thus the origin of the oil price shocks should be considered. According to Hamilton (2009a,b) there are demand driven, as well as supply driven oil price shocks. Kilian (2009) disentangles demand-side oil price shocks, into aggregate demand oil price shock and precautionary demand oil price shocks (or oil specific demand shocks) and he argues that "the response of aggregate stock returns may differ greatly depending on the cause of the oil price shock" (p.1268). For example, according to Kilian and Park (2009) the supply-side oil price shocks and the oil specific demand shocks trigger a negative response from the stock markets, whereas the reverse is true for the aggregate demand oil price shocks. In the same line of reasoning, Lippi and Nobili (2009) show that supply-side oil price shocks exercise a negative effect in the economy, whereas a positive effect is observed from demand-side oil price shocks. Other authors who have considered the origin of the oil price shocks in their studies include Kilian and Lewis (2011), Filis et al. (2011), Apergis and Miller (2009), Lescaroux and Mignon (2009), Kilian (2008a) and Barsky and Kilian (2004), among others.

Having established that there is a growing literature that considers the empirical relationship between oil price shocks and stock market developments, we should point out that we know little about the effects of these shocks on different industrial sector indices. Overall, it is expected that a positive change in oil prices will increase production costs, considering that oil (along with its by-products) represents one of the most basic production inputs (Arouri and Nguyen, 2010; Backus and Crucini, 2000; Kim and Loungani, 1992). These increased production costs will result in increased prices, leading, in turn, to lower demand and thus lower consumption (negative income effect) (see, for example, LeBlanc and Chinno, 2004; Hooker, 2002; Abel and Bernanke, 2001; Hamilton, 1996; Hamilton, 1988; Barro, 1984, and among other). Furthermore, the lower demand will result to a reduction in output level and thus lower expected cash flows. As a consequence and taking into considering that stock prices are affected by the value of the discounted future cash flows, we would expect stock prices to exhibit a bearish behavior (Sadorsky, 1999; Jones and Kaul, 
1996). We should not lose sight of the fact though that the aforementioned oil price effects are far from definite as they depend on the status of the country (i.e. whether it is oilimporting or oil-exporting) and on the source that causes oil prices to change (i.e. supply or demand driven), as aforementioned.

The examination of oil price shocks on sector level is essential as there may be industry specific responses to oil price shocks, or even the magnitude of the responses may differ among the various sectors. Investors, as well as, sector's participants need to be aware of these responses. In addition, aggregate stock market indices of different countries do not tell a complete story, as the industrial base of each country could be significantly different. Thus, the results which are based on aggregate indices should be treated cautiously. Narayan and Sharma (2011), Nandha and Faff (2008), Boyer and Filion (2007), El-Sharif et al. (2005), Hammoudeh and Li (2005) and Sadorsky (2001) are some of the few studies that considered the effects of oil price shocks on industrial sector indices. A common finding on all these studies is that oil price increases positively affect the stock returns of Oil\&Gas companies. El-Sharif et al. (2005), though, suggest that this relationship is weak for the UK Oil\&Gas sector. In addition, Hammoudeh and Li (2005) report the opposite effect in the case of the US Transportation index. Similar findings are reported in Nandha and Brooks (2009). Furthermore, Nandha and Faff (2008) analyse 35 Datastream $^{\circledR}$ global industry indices for the period April 1983 to September 2005 and report that positive oil price shocks have a negative impact on equity returns for all sectors except Mining and Oil\&Gas industries. Narayan and Sharma (2011), on the other hand, use a simple univariate GARCH model to examine the relationship between oil price and firm returns for 560 US firms listed in the NYSE. Their findings suggest that oil prices exercise asymmetric effects on stock returns, depending on the sector they are listed in. More specifically, the Supply, Manufacturing, Food, Chemical, Medical, Computer, Transportation, Banking, Real Estate and General Services sectors exhibit a negative response to positive oil price shocks. By contrast, the Energy sector exhibits a positive response to positive oil price shocks, whereas results are inconclusive for the Electricity, Engineering and Financial sectors. Nevertheless, the authors argue that the aforementioned results are firm size dependent. In particular, small firms' stock prices of any sector tend to be favoured by oil price increases, whereas the reverse holds for the larger firms.

Kilian and Park (2009), also considers industry-level stock returns by examining four US industrial sectors (Petroleum and Natural Gas, Automobile and Trucks, Retails and Precious Metals), suggest that oil price shocks exercise different effects on several industrial 
sectors. Thus, investors need to consider differences in the responses across industries in terms of their portfolio adjustments in response to oil price changes.

In addition, Elyasiani et al. (2011), using a univariate GARCH model, examine oil price shocks and industry stock returns of thirteen US industries, dividing them in four categories, namely, oil-users, oil-substitute, oil-related and financial industries. They suggest that oil prices exercise a direct effect on oil-related and oil-substitute industries, whereas this effect is indirect for the oil-users and financial industries. Overall, the effects are positive for the oil-substitute and oil-related industries, whereas it is negative for the oil-users and financial industries.

Similar findings are reported for the European markets. In particular, Scholtens and Yurtsever (2012) suggest that the impact of oil prices shocks at 38 industries in 15 European countries substantially differ along the industries over the period 1983-2007. Their study shows that most industries would benefit from negative oil price shocks; however, Oil, Mining and Gas industries would benefit from oil price increases.

Arouri and Nguyen (2010) second these conclusions suggesting that the reactions of stock returns to oil price changes differ depending on the industrial sector. More specifically, they investigate the relationship between oil prices and stock returns in Europe using data from the Dow Jones Stoxx 600 and 12 European industrial sector indices and report strong significant linkages between oil price changes and stock prices. More specifically, they find that the Food and Beverages, Health Care and Technology sectors respond negatively to oil price increases, whereas the response is positive for the Financial, Oil\&Gas, Industrials, Basic Materials and Personal and Household Goods sectors. However, in a subsequent study, Arouri (2011) considers the European industrial sector indices and finds that a positive oil price shock tends to appreciate the stock index of the Oil\&Gas sector; it has a negative effect on the Financials and Consumer Goods sectors, whereas no effect is observed in the Industrial sector.

Turning to the net oil-exporting countries, Mohanty et al. (2011) examine the relationship between oil price and stock market returns in Gulf Cooperation Council (GCC) countries using country-level, as well as, industry-level data. They report that the responses of industry-specific returns to oil shocks are significantly positive for most industries. It is evident that the results from oil-exporting countries are significantly different from those from oil-importing countries.

The aforementioned studies, though, have ignored the importance of examining this relationship in a dynamic environment. Thus, the paper comes to fill this void, by examining 
the relationship between oil price changes and European sector stock market returns, in a time-varying multivariate heteroskedastic framework, considering the origin of the oil price shocks.

The European sector stock market indices were chosen due to the characteristics of the energy sector in Europe. According to the EU Energy Policy Factsheet (2011), EU's import dependency on oil has increased in the recent years and the evidence suggests that it will keep growing in the next decades, as well. They estimate that by 2030 the EU will import more than $70 \%$ of its oil and gas demand. In addition, oil represents about $60 \%$ of the total EU energy imports. Considering that the energy prices are expected to rise in the next decades, we are able to understand the importance of oil in EU economy and thus to the stock market sectors. Another interesting point about EU is that its member states have significantly different dependency ratios of oil, where some countries has a ratio as low as $20 \%$, whereas for some other countries this ratio can reach the level of $80 \%$ or beyond. However, as suggested by the EU Energy Policy Factsheet (2011), national energy decisions can exert an impact to other member states, due to the energy interdependence among EU member states. Thus, the investigation of the relationship between oil and the European sector stock market indices in a time varying framework is not only intriguing but current, as well.

In short, the findings are as follows: i) the relationship between oil price returns and stock returns are industry specific, ii) the consideration of the origins of oil price shocks is important, as they trigger different responses from the industrial sectors and iii) during the 2008 financial crisis, which triggered an aggregate demand oil price shock, the Health, Technology, Telecommunications and Utilities sectors offer hedging opportunities in portfolios consisted of oil commodity and stocks.

Furthermore, we do not offer support to the evidence provided by the current literature, which mainly suggests that all industrial sectors, except the Oil\&Gas and Mining, respond negatively to positive oil price shocks. We argue that the response is not constant and it depends on the origin of the oil price shock. These findings are important for traders and stock market analysts dealing with oil markets.

The rest of this paper is organised as follows: Section 2 presents the econometric model employed. Section 3 discusses the data, while Section 4 reports the empirical results. Section 5 concludes the paper and discusses points for further research. 


\section{Methodology}

In the paragraphs follow, a multivariate autoregressive conditionally heteroskedastic framework is defined, under which we construct monthly time-varying estimates of the variance and the correlation for the oil prices and the 10 industrial sector indices. The term time-varying throughout the paper expresses the time varying attribute of the conditional variance. It does not convey that the parameters of the model are allowed to change over time. $^{3}$

Let $\mathbf{y}_{t}$ refer to the $(n \times 1)$ multivariate discrete time real-valued stochastic process under investigation, and $I_{t-1}$ define the available to the investors information set when they make their investment decisions at time $t-1$. The vector $\mathbf{y}_{t}$ can be decomposed into the relevant expected return to the investors given $I_{t-1}, E_{t-1}\left(\mathbf{y}_{t}\right)=\boldsymbol{\mu}_{t}$, and the innovation process, $\boldsymbol{\varepsilon}_{t}=\mathbf{y}_{t}-\boldsymbol{\mu}_{t}$. The covariance matrix of the innovation process, conditional to $I_{t-1}$, can be defined as $V_{t-1}\left(\mathbf{y}_{t}\right) \equiv \mathbf{H}_{t}$. Moreover, we assume that the innovation process is decomposed to $\boldsymbol{\varepsilon}_{t}=\mathbf{H}_{t}^{1 / 2} \mathbf{z}_{t}$ where $\mathbf{z}_{t}$ is an $(n \times 1)$ vector process, which is independently normally distributed such that $E\left(\mathbf{z}_{t}\right)=\mathbf{0}$ and $E\left(\mathbf{z}_{t} \mathbf{z}_{t}^{\prime}\right)=\mathbf{I}$. Thus, the innovation process conditional to $I_{t-1}$ is also multivariate normally distributed with a time-varying variance matrix, or $\boldsymbol{\varepsilon}_{t} \mid I_{t-1} \sim N\left(0, \mathbf{H}_{t}\right)$.

Bollerslev et al. (1988) introduced the Diag-VECH GARCH model, which ensures the positive definiteness of the time-varying variance matrix, $\mathbf{H}_{t}$, and requires the estimation of fewer parameters compared to other specifications, i.e. Engle and Kroner's (1995) BEKK, Engle's et al. (1986) VECH, etc. The aim is to consider a VECH model which permits parsimony and retains ease of interpretation in parameters. Since the VECH model contains a large number of parameters, we improve parsimony using a Diag-VECH version which results in a parameter size reduction (Xekalaki and Degiannakis, 2010); that is an important condition for our case ${ }^{4}$.

For $\left\{\mathbf{y}_{t}\right\}$ denoting the vector with the log-returns of the oil and the 10 industrial sector indices on a monthly frequency, the Diag-VECH GARCH model can be presented as ${ }^{5}$ :

\footnotetext{
${ }^{3}$ For example, Baumeister and Peersman (2012) estimate a time-varying parameter VAR model with stochastic volatility, allowing for time variation in both the coefficients and the variance-covariance matrix. Nevertheless, the estimation of a time-varying parameter model does not fall into the scope of the present study.

${ }^{4}$ Under the Diag-VECH GARCH model, the number of parameters is reduced, so no interaction is allowed between the different conditional variances and covariances. The drawback of Diag-VECH is that it does not capture volatility spillover effects between markets; nevertheless, this is not examined in the present study.

${ }^{5}$ Kilian and Park (2009) provide evidence that oil price shocks tend to have a lagged effect in the economy and the real stock returns do not adjust to oil price shocks on impact. Moreover, Campbell et al. (1997) and
} 


$$
\begin{aligned}
& \mathbf{y}_{t}=\boldsymbol{\beta}+\boldsymbol{\varepsilon}_{t} \\
& \boldsymbol{\varepsilon}_{t}=\mathbf{H}_{t}^{1 / 2} \mathbf{z}_{t} \\
& \mathbf{z}_{t} \sim N(\mathbf{0}, \mathbf{I}) \\
& \operatorname{vech}\left(\mathbf{H}_{t}\right)=\operatorname{vech}\left(\widetilde{\mathbf{A}}_{\mathbf{0}}\right)+\operatorname{vech}(\widetilde{\mathbf{A}}) \circ \operatorname{vech}\left(\boldsymbol{\varepsilon}_{t-1} \boldsymbol{\varepsilon}_{t-1}^{\prime}\right)+\operatorname{vech}(\widetilde{\boldsymbol{\Gamma}}) \circ \operatorname{vech}\left(\widetilde{\boldsymbol{\varepsilon}}_{t-1} \widetilde{\boldsymbol{\varepsilon}}_{t-1}^{\prime}\right)+\operatorname{vech}(\widetilde{\mathbf{B}}) \circ \operatorname{vech}\left(\mathbf{H}_{t-1}\right),
\end{aligned}
$$

where $\boldsymbol{\mu}_{t}=\boldsymbol{\beta}^{\prime}=\left(\begin{array}{llll}\beta_{0} & \beta_{1} & \ldots & \beta_{11}\end{array}\right), N(\mathbf{0}, \mathbf{I})$ is the multivariate standard normal density function, and the symbol $\circ$ denotes the Hadamard product. The $\boldsymbol{\beta}, \tilde{\mathbf{A}}_{\mathbf{0}}, \tilde{\mathbf{A}}, \tilde{\boldsymbol{\Gamma}}$ and $\widetilde{\mathbf{B}}$ are matrices with parameters to be estimated. Each $i^{\text {th }}$ diagonal element of the time-varying variance matrix $\mathbf{H}_{t}$ is

$$
\sigma_{i, t}^{2}=a_{i, i}+\widetilde{a}_{i, i} \varepsilon_{i, t-1}^{2}+\gamma_{i, i} \varepsilon_{i, t-1}^{2} d_{i, t-1}+\tilde{b}_{i, i} \sigma_{i, t-1}^{2}
$$

whereas, each $(i, j)^{t h}$ non-diagonal element of $\mathbf{H}_{t}$ is

$$
\sigma_{i, j, t}=a_{i, j}+\widetilde{a}_{i, j} \varepsilon_{i, t-1} \varepsilon_{j, t-1}+\gamma_{i, j} \varepsilon_{i, t-1} d_{i, t-1} \varepsilon_{j, t-1} d_{j, t-1}+\tilde{b}_{i, j} \sigma_{i, j, t-1},
$$

where $d_{i, t-1}$ denotes the indicator function, i.e. $d_{i, t-1}=1$ if $\varepsilon_{i, t-1}<0$, and $d_{i, t-1}=0$ otherwise. The $a_{i, j}, \tilde{a}_{i, j}, \gamma_{i, j}$ and $\tilde{b}_{i, j}$ are the $(i, j)^{t h}$ elements of the $\tilde{\mathbf{A}}_{\mathbf{0}}, \tilde{\mathbf{A}}, \tilde{\boldsymbol{\Gamma}}$ and $\tilde{\mathbf{B}}$ matrices, respectively. The Diag-VECH model requires the estimation of 275 parameters ${ }^{6}$, or $n+2(n+1) n$, for $n=11$. For each month $t$, the time-varying correlation between oil logreturns and $j^{\text {th }}$ industrial sector index log-returns is computed as:

Cochrane (2005) suggest including lags of oil price changes and/or stock returns in the conditional mean equation. Therefore, a more specified model could be a VAR(1) model for the conditional mean: $\mathbf{y}_{t}=\boldsymbol{\beta}+\mathbf{B} \mathbf{y}_{t-1}+\boldsymbol{\varepsilon}_{t}$, where $\mathbf{y}_{t}=\left[\begin{array}{lll}y_{1, t} & \ldots & y_{11, t}\end{array}\right]^{\prime}, \boldsymbol{\varepsilon}_{t}=\mathbf{H}_{t}^{1 / 2} \mathbf{z}_{t}$ and $\mathbf{z}_{t} \sim N(\mathbf{0}, \mathbf{I})$. Or else, since a VAR requires the estimation of a large number of parameters, a possibility would be to use a bivariate framework for each of the stock returns and the oil price measure (i.e. Elder and Serletis, 2010).

However, in the Diag-VECH GARCH model, the $(i, j)^{\text {th }}$ non-diagonal element of $\mathbf{H}_{t}$ expresses the timevarying correlation of $\left(\varepsilon_{i, t}, \varepsilon_{j, t}\right) \equiv\left(y_{i, t}-\beta_{0, i}, y_{j, t}-\beta_{0, j}\right)$, i.e. the correlation across time of the de-mean log-returns, which is the aim of this paper. On the contrary, in the case of including lags of the endogenous variables in the conditional mean, the $(i, j)^{\text {th }}$ non-diagonal element of $\mathbf{H}_{t}$ would express the time-varying correlation of the innovations-residuals; in other words, the correlation across time of the unexplained part of the returns and this does not fall within the scope of this paper. I.e. under a VAR(1) specification for the conditional mean, the $(i, j)^{t_{h}} \quad$ non-diagonal element of $\mathbf{H}_{t}$ expresses the time-varying correlation of $\left(\begin{array}{l}\varepsilon_{i, t} \\ \varepsilon_{j, t}\end{array}\right) \equiv\left(\begin{array}{l}y_{i, t}-\beta_{0, i}-\beta_{1, i} y_{i, t-1}-\ldots-\beta_{1, j} y_{j, t-1} \\ y_{j, t}-\beta_{0, j}-\beta_{1, j} y_{i, t-1}-\ldots-\beta_{1, j} y_{j, t-1}\end{array}\right)$. In the case of a bivariate model for each of the stock returns and the oil price measure, the $(i, j)^{\text {hh }}$ non-diagonal element of $\mathbf{H}_{t}$ expresses the time-varying correlation of $\left(\begin{array}{c}\varepsilon_{\text {ind }, t} \\ \varepsilon_{\text {oil }, t}\end{array}\right) \equiv\left(\begin{array}{l}y_{\text {ind }, t}-\beta_{0, \text { ind }}-\beta_{1, \text { ind }} y_{\text {ind }, t-1}-\beta_{2, \text { ind }} y_{\text {oil }, t-1} \\ y_{\text {oil }, t}-\beta_{0, o \text { oil }}-\beta_{1, o i l} y_{\text {ind }, t-1}-\beta_{2, o i l} y_{\text {oil }, t-1}\end{array}\right)$.

${ }^{6}$ The coefficient estimates of the model are available upon request. 
$\rho_{1, j, t}=\frac{\sigma_{1, j, t}}{\sqrt{\sigma_{1, t}^{2} \sigma_{j, t}^{2}}}=\frac{a_{1, j}+\tilde{a}_{1, j} \varepsilon_{1, t-1} \varepsilon_{j, t-1}+\gamma_{1, j} \varepsilon_{1, t-1} d_{1, t-1} \varepsilon_{j, t-1} d_{j, t-1}+\tilde{b}_{1, j} \sigma_{1, j, t-1}^{2}}{\left.\sqrt{\left(a_{1,1}+\tilde{a}_{1,1} \varepsilon_{1, t-1}^{2}+\gamma_{1,1} \varepsilon_{1, t-1}^{2} d_{1, t-1}+\tilde{b}_{1,1} \sigma_{1, t-1}^{2}\right)\left(a_{j, j}+\tilde{a}_{j, j} \varepsilon_{j, t-1}^{2}+\gamma_{j, j} \varepsilon_{j, t-1}^{2} d_{j, t-1}+\tilde{b}_{j, j} \sigma_{j, t-1}^{2}\right.}\right)}$.

\section{Data Description}

The time-varying correlations, $\rho_{1, j, t}$, are estimated using monthly data from January 1992 to December 2010 on European industrial sector indices. The time frame was chosen based on the data availability.

In particular, we consider the following industrial sector indices, which have been constructed by Dow Jones: Financials, Oil\&Gas, Retail, Consumption Goods, Health, Industrial, Basic Materials, Technology, Telecommunications and Utilities. The industrial sector indices data have been extracted from Datastream ${ }^{\circledR 7}$ and their choice was driven by data availability and the need of the authors to have industries which are oil-related, oilsubstitutes and non oil-related. Furthermore, we use monthly data for the same time period for Brent crude oil prices. This type of oil is chosen, as a proxy of world oil price, due to the fact that it represents the $60 \%$ of the world oil daily consumption (Maghyereh, 2004). The data for the Brent crude oil prices have been extracted from the Energy Information Administration (EIA). All prices are expressed in nominal dollar terms, following Hamilton $(1983)^{8}$, and in log-returns.

\section{Empirical Findings}

The number of lags in the variance matrix $\mathbf{H}_{t}$ has been selected according to the Schwarz (1978) information criterion and the sequential modified likelihood ratio (Lütkepohl, 2007). Tests that provide evidence to support our model specification have been conducted, i.e. multivariate Q-statistic for residual serial correlation (Lütkepohl, 1991), testing for presence of $\mathrm{ARCH}$ effects in the residuals ${ }^{9}$; see for example Hacker and Abdulnasser (2005), Tse (2002) and Xekalaki and Degiannakis (2010). The Diag-VECH GARCH model is estimated taking into consideration the Bollerslev and Wooldridge (1992)

\footnotetext{
${ }^{7}$ The industrial sector indices have been computed by Stoxx Limited. The countries which are covered by these indices are: Austria, Belgium, Denmark, Finland, France, Germany, Greece, Iceland, Ireland, Italy, Luxemburg, Netherlands, Norway, Portugal, Spain, Sweden, Switzerland and UK. For more information on the construction of the indices please refer to http://www.stoxx.com/indices/types/sector.html

${ }^{8}$ Hamilton defends his use of the nominal oil price rather than a real measure on two grounds: (1) the nominal oil price is the exogenous variable which belongs in a reduced-form regression because it is the variable under institutional control which forms the shocks; and (2) he does not believe that the expected change in the relative shadow price of oil equals the market price divided by a contemporaneous price index (Hamilton, 1983, p.238).

${ }^{9}$ The outputs of the test statistics are available upon request.
} 
robust quasi-maximum likelihood standard errors. Under the standard regularity conditions, the quasi-maximum likelihood technique provides consistent estimates of the parameters even when the innovations are non-normally distributed.

The time-varying plots for the whole period under investigation are presented in Figure $1^{10}$. In addition Table 1 shows the descriptive statistics of the time-varying correlation series.

\section{[INSERT FIGURE 1 ABOUT HERE]}

\section{[INSERT TABLE 1 ABOUT HERE]}

Overall, the average correlation figures are positive for the majority of the indices, with one exception, that of the Telecommunications index. However, the correlation over time between oil returns and industrial sector indices returns is not constant. Although the behaviour of the figures is different for the various industries under examination, some similar patterns can be detected.

The time-varying correlations between oil price changes and the Financial, Consumption Goods and Materials sectors returns share common fluctuations. The Retail and Technology sectors returns seem to exhibit common patterns in their correlation with the oil price changes, as well. The Telecommunications and Utilities sectors returns are also having some similarities in their behaviour. With reference to the Oil\&Gas sector returns it is interesting to observe the low mean value and volatility of its correlation with the oil prices. The correlation fluctuates around the level of 0.2-0.3, although there is a trough at the level of 0.07 at the end of 2004. The highest volatilities, in a descending order, are observed in the time-varying correlation between oil price changes and Consumption Goods, Utilities, Technology and Retail sectors returns. Such finding is not surprising for most of the indices, considering the importance of oil on the latter sectors. The returns of the Industrial sector exhibit a very low volatility in correlation fluctuations over time (the standard deviation is 0.0687). This finding does not seem plausible, as the Industrial sector is expected to be heavily influenced from oil price returns ${ }^{11}$. Nonetheless, as Arouri (2011) argues, the firms in the Industrials sector engage in effective hedging strategies which reduce the effects of adverse oil price movements. Furthermore, all correlations are positive on average with the exception of the Telecommunications index returns. Henriques and Sadorsky (2008) suggest

\footnotetext{
${ }^{10}$ The Diag-VECH GARCH model was estimated for higher sampling frequencies, i.e. weekly and daily sampling frequencies, but the results are qualitatively similar. For purposes of illustration the monthly sampling frequency is proposed.

${ }^{11}$ The oil price returns are estimated as de-meaned log-returns; i.e. $\varepsilon_{1, t}=y_{1, t}-\beta_{0}$, for $y_{1, t}$ denoting the oil logreturns and $\beta_{0}$ being the first element of the vector $\boldsymbol{\beta}$ in equation (1).
} 
that higher oil prices create uncertainty in Telecommunications investments and thus make the stocks returns in this sector to be riskier. Finally, almost all correlations fluctuate in both positive and negative levels. Exceptions include the Oil\&Gas, as well as, the Industrial sector as their correlations fluctuate in positive levels only.

The aforementioned preliminary results disagree, in part, with the past literature. Previous findings document that there is a negative relationship between oil price returns or oil price shocks and industrial sector index returns, such as the Supply, Transportation, Medical, Financial and the Consumer Goods (see Arouri, 2011; Narayan and Sharma, 2011; Kilian and Park, 2009) and that there is no relationship between oil price changes and the returns of the Industrials and Engineering sectors (see Arouri, 2012; Narayan and Sharam, 2011). On the other hand, the time-varying correlation estimates are in line with the studies of Scholtens and Yurtsever (2012) and Nandha and Faff (2008) who report a positive relationship between oil price returns or oil price shocks and the Oil\&Gas and Mining sectors returns. Nevertheless, the aforementioned studies do not examine the relationship over time and, thus, they do not take into consideration the dynamic relationship between the industrial sector indices and oil prices.

Next, we identify the origins of the oil price shocks, which cause a change in the correlation between returns of oil and industrial sector indices, proceeding to the analysis on several sub-periods. The origin of the oil price shocks that are referred to the following subperiods have been suggested by Hamilton (2009a,b) and Kilian (2009).

Figure 2 plots the time-varying correlations between returns of oil prices and industrial sector indices for the sub-period 1992-1996. A period with several changes in oil production volume, due to the increase in Kuwait's production to defend OPEC's quota in 1992 or the Nigerian oil workers strike, for example, in 1994. This period is also characterised by the withdrawal of two countries from OPEC, namely Ecuador and Gabon, in 1992 and 1995, respectively. In short, this is a period with several supply-side oil price shocks.

\section{[INSERT FIGURE 2 ABOUT HERE]}

[INSERT TABLE 2 ABOUT HERE]

The correlation level during this period is low positive, on average, for almost all sectors. For the Telecommunications sector the correlation is almost zero (see Table 2). Furthermore, it is evident that some of the sectors tend to fluctuate in both negative, as well as, positive correlation levels (i.e. Financials, Consumer Goods, Materials and Telecommunications). The lowest volatility is observed in the correlation with the Oil\&Gas 
index, suggesting a stable relationship between the sector and oil prices during this period. In addition, a small upward trend is evident for several industrial sector indices, including the Financial, the Consumer Goods and the Materials sectors. An almost constant positive correlation at the level of 0.25-0.3 exists for the Oil\&Gas, the Health and the Utilities sectors, whereas negative trend is observed for the Retail, Technology and Telecommunications sectors. Overall, the supply-side oil price shocks that took place during this period resulted in low correlation figures (mainly positive) between oil prices and the industrial sector indices. Nevertheless, the correlation trends seem to differ depending on the sector.

Figure 3 and Table 3 refer to the sub-period 1997-1999. The main event during this period is the Asian economic crisis, which caused an aggregate demand oil price shock. Nonetheless, there were several supply-side events that took place in the latter part of this period.

\section{[INSERT FIGURE 3 ABOUT HERE]}

[INSERT TABEL 3 ABOUT HERE]

During this period all correlations, on average, are low positive and they are around the level of 0.2. Exceptions are the Telecommunications and Technology sectors which exhibit an average correlation of almost zero. The Utilities sector is also showing zero correlation after 1998. The Asian crisis caused a small positive increase in correlation levels, especially for the Financials, Oil\&Gas, Consumer Goods, Health, Retail and Utilities sectors. This finding is expected as the Asian crisis caused a reduction in oil prices, as well as, a downturn in economic activity and stock market performance. In addition, both oil-intensive and non-oil-intensive sectors have been affected by the Asian crisis in a similar fashion. The supply-side shocks of 1998-1999, which were caused by the OPEC oil supply cuts, resulted in the reduction on the correlation levels between oil prices and industrial sector indices to almost zero correlation. Exception is the Oil\&Gas sector, where a low to moderate positive correlation is still observed during these supply-side oil price shocks. On the whole, the supply-side oil price shocks of this period seem to create low correlation levels, whereas the evidence suggest that aggregate demand oil price shock (i.e. the Asian crisis) has triggered an increase in the level of correlation with all correlation trends exhibiting an upward trend.

The next period under examination is the sub-period 2000-2003. Three main events are identified in this period, namely, the housing and dot-com bubbles in 2000, the 9/11 terrorist attack in the US in 2001 and the second war in Iraq in 2003. The two latter events triggered precautionary demand oil price shocks, whereas the first event caused an aggregate demand oil price shock. 


\section{[INSERT FIGURE 4 ABOUT HERE]}

[INSERT TABLE 4 ABOUT HERE]

Once again a stable and low positive correlation is observed for eight sectors (see Figure 4 and Table 4). The Telecommunications and Technology sectors experience an average negative correlation during this period. For most indices the two events that caused precautionary demand oil price shocks (9/11 terrorist attack and the second war in Iraq) resulted in a reduction in correlation levels. Due to the dot-com bubble, the correlation between the returns of the Technology sector and the oil prices is expected to be strongly negative in 2000, but we do not report such evidence. Instead, a moderate negative correlation in 2000 is observed with the Telecommunications sector.

Continuing the analysis, 2004-2007 is the sub-period when the Chinese economy started to experience remarkable growth, causing a significant increase in oil prices.

\section{[INSERT FIGURE 5 ABOUT HERE] \\ [INSERT TABLE 5 ABOUT HERE]}

The aggregate demand oil price shock of this period resulted in a positive correlation between the returns of oil prices and the industrial sector indices (see Figure 5 and Table 5). In addition, an upward trend in all correlation figures is observed. Even the sectors returns that previously exhibited a negative correlation, they fluctuated in the positive region especially during the years 2006-2007. It is interesting that the highest correlation, apart from the Oil\&Gas sector (as expected), is observed with the Consumer Goods sector. Hence, the Chinese economic boom had also a positive impact on consumer goods sector in Europe. Furthermore, Utilities, Health and Financials sectors are also exhibiting increased correlation suggesting that these sectors were also experiencing an upward trend during that period.

The final sub-period that we consider is 2008-2010, when the world experienced the global financial crisis. In addition, this sub-period covers the start of the debt crisis in Euro zone. During this period we observe a significant decline in oil prices, which was caused by the decline in oil demand (aggregate demand oil price shock).

\section{[INSERT FIGURE 6 ABOUT HERE] \\ [INSERT TABLE 6 ABOUT HERE]}

All figures show either a peak or a trough during the peak-time of the financial crisis (2008:Q3-2008:Q4), whereas we do not observe any peaks or troughs at the start of the debt crisis in 2010. Although a significant change in correlations is observed at the mid and late 2008, the behaviour is different for various sectors. In particular, a very high increase in correlation is evident between oil price changes and the returns of the Financial, Consumer Goods and Materials sectors. The increase in the Industrial and Oil\&Gas sectors is small. Furthermore, we observe an important reduction in correlation between the oil price changes 
and the returns of the Health, Technology, Telecommunications and Utilities sectors. The Retail sector, on the other hand, exhibits a small drop. Therefore, the 2008 financial crisis did impact the correlation levels between the sectors and oil prices returns significantly, although not in the same fashion.

The analysis of the time-varying correlations generates some important conclusions. Overall, the level of correlation, as well as, its direction is not the same for all sectors. Furthermore, the correlation does not remain constant over time, implying a time-varying relationship between the returns of oil prices and industrial sector indices. In addition, correlations change in respond to different oil price shocks. Supply-side oil price shocks cause low positive but decreasing correlation levels (in most cases). During periods of supply-side shocks, low volatility of the time-varying correlation is observed. Furthermore, the precautionary demand shocks cause, for the majority of the indices, a reduction in the correlation level, leading to very low or even zero correlations. Finally, the aggregate demand oil price shocks tend to generate important changes in the correlation levels. For example, the period of the Chinese economic growth led to a stable increase in the correlation level of all indices. On the other hand, the 2008 financial crisis initiated hard shifts in the correlation levels, either upwards or downwards.

Overall, (i) the supply-side oil price shocks result in low to moderate positive correlation levels, (ii) the precautionary demand oil price shocks lead to almost zero correlation levels, whereas (iii) the aggregate demand oil price shocks generate significant changes in the correlation levels. Hence, the origin of the oil price shock is important determinant of the correlation level and direction and it should be carefully considered by studies when examining the relationship between stock and oil prices.

Prominent among the findings is the fact that in periods of world economic turmoil, such as the 2008 financial crisis, where the majority of the asset prices tend to move in the same direction (downwards), there are sectors, i.e. Health, Technology, Telecommunications and Utilities, that offer diversification opportunities in portfolios consisted of oil commodity and stocks.

\section{Concluding Remarks}

The paper examines the relationship between the returns of oil prices and industrial sector indices in a time-varying heteroskedastic environment, taking into consideration the origin of the oil price shocks. In particular, we consider the equity returns from 10 European industrial sector indices to examine their relationship with oil price fluctuations. The time- 
varying correlations are estimated by a Diag-VECH GARCH model. Following a similar approach with Filis et al. (2011) and using the oil price shocks to assess whether changes in the aforementioned time-varying correlation could be due to the different origins of the oil price shocks, the present study adds to the existing literature as it provides some new insights in the study of oil prices and industrial sector stock market returns. By doing so, we also extend the findings by Kilian (2009) and Kilian and Park (2009) who mainly concentrate of the effects of oil price shocks on industrial sectors stock market returns in a Structural VAR environment rather than in a time-varying one. In addition, as this is the first study that examines the aforementioned relationship in a time-varying environment, we extend the findings of the existing literature that focuses on the relationship between industrial stock market returns and oil price returns in a static environment, as these have been presented in Section 1.

The summarized findings are as follows. First, the relationship between oil price fluctuations and stock returns is examined in a time-varying environment, as it does not remain constant throughout time. Second, the relationships are industry specific and thus if we solely consider aggregate stock market indices, rather than industrial sector indices, then we are not able to paint a complete picture. Third, the link between the returns of oil prices and industrial sector indices is significantly influenced by the origin of the oil price shock. In particular, we can suggest that the supply-side oil price shocks result in low to moderate positive correlation levels, the precautionary demand oil price shocks lead to almost zero correlation levels, whereas the aggregate demand oil price shocks generate significant changes (either upwards or downwards) in the correlation levels. Finally, in periods of world economic turmoil, such as the 2008 financial crisis, where investors choose between alternatives in an effort to minimise their risk, equity sectors such as the Health, Technology, Telecommunications and Utilities sectors offer some diversification opportunities in portfolios consisted of oil commodity and stocks; a finding of particular importance for traders and stock market analysts.

The results partly agree with previous studies, such as these by Scholtens and Yurtsever (2012) and Nandha and Faff (2008) who also report a positive relationship between oil price changes or oil price shocks and the Oil\&Gas sector returns. By contrast, the findings disagree with the past studies which suggest that there is a negative relationship between oil price returns or oil price shocks and the Supply, Transportation, Medical, Financial and the Consumer Goods sectors returns and that there is no relationship between oil price fluctuations or shocks and the Industrials and Engineering sectors returns (see Arouri, 2012; 
Narayan and Sharma, 2011; Kilian and Park, 2009, among others). Nevertheless, these studies did not consider the time-varying fluctuations of the correlation and thus a direct comparison should be treated with caution.

Further research may (i) examine the relationship between the returns of oil prices and industrial sector indices for oil-importing and oil-exporting countries, and (ii) explore other explanatory variables that might influence this time-varying correlation. The Diag-VECH model estimated in our study does not capture volatility spillover effects between markets. The induction of spillover effects between markets (in the same fashion with Elder and Serletis, 2010, approach) is an interesting topic for further research. Another avenue for further research could include the forecasting ability of oil price innovations on stock market returns. Finally, the examination of the time-varying correlation between each of the different oil price shocks and stock market industrial sector returns is another exciting area for further study.

Disclaimer: The views expressed are those of the authors and should not be interpreted as those of their respective institutions. The authors are solely responsible for any remaining errors and deficiencies.

\section{References}

Abel, B.A. and Bernanke, B.S. (2001). Macroeconomics. Addison Wesley Longman Limited, Boston, Massachusetts.

Aloui, C. and Jammazi, R. (2009). The effects of crude oil shocks on stock market shifts behaviour: a regime switching approach. Energy Economics, 31, 789-799.

Apergis, N. and Miller, S.M. (2009). Do structural oil-market shocks affect stock prices? Energy Economics, 31, 569-575.

Arouri, M.E.H. (2011). Does crude oil move stock markets in Europe? A sector investigation. Economic Modelling, 28, 1716-1725.

Arouri, M.E.H. (2012). Stock returns and oil price changes in Europe: A sector analysis. The Manchester School, 80(2), 237-261.

Arouri, M.E.H. and Nguyen, D. K. (2010). Oil prices, stock markets and portfolio investment: Evidence from sector analysis in Europe over the last decade. Energy Policy, $38,4528-4539$. 
Arouri, M. E. H. and Rault, C. (2012). Oil prices and stock markets in GCC countries: Empirical evidence from panel analysis. International Journal of Finance and Economics, in press.

Arouri, M.E.H., Jouini, J. and Nguyen, D. K. (2012). On the impacts of oil price fluctuations on European equity markets: Volatility spillover and hedging effectiveness. Energy Economics, 34, 611-617.

Backus, K.D. and Crucini, M.J. (2000). Oil prices and the terms of trade. Journal of International Economics, 50, 185-213.

Barro, J.R. (1984). Macroeconomics. Wiley and Sons, New York.

Barsky, R. B. and Kilian, L. (2004). Oil and the Macroeconomy since the 1970s. Journal of Economic Perspectives, 18(4), 115-34.

Basher, S.A. and Sadorsky, P. (2006). Oil price risk and emerging stock markets. Global Finance Journal, 17 (2), 224-251.

Baumeister, C. and G. Peersman (2012). Time-Varying Effects of Oil Supply Shocks on the U.S. Economy, Bank of Canada, Working Paper.

Bernanke, B. S., Gertler, M. and Watson, M. (1997). Systematic Monetary Policy and the Effects of Oil Price Shocks. Brookings Papers on Economic Activity, 1, 91-142.

Bjornland, H. C. (2009). Oil price shocks and stock market booms in an oil exporting country. Scottish Journal of Political Economy, 56 (2), 232-254.

Bharn, R. and Nikolovann, B. (2010). Global oil prices, oil industry and equity returns: Russian experience. Scottish Journal of Political Economy, 57 (2), 169-186.

Blanchard, O. and Galı, J. (2007). The Macroeconomic Effects of Oil Price Shocks: Why are the 2000s so different from the 1970s? NBER Working Paper No. 13368.

Bollerslev, T. and Wooldridge, J.M. (1992). Quasi-maximum Likelihood Estimation and Inference in Dynamic Models with Time-Varying Covariances. Econometric Reviews, $11,143-172$.

Bollerslev, T., Engle, R.F. and Wooldridge, J. M. (1988). A Capital Asset Pricing Model with Time-Varying Covariances. Journal of Political Economy, 96, 116-131.

Boyer, M.M. and Filion, D. (2007). Common and fundamental factors in stock returns of Canadian oil and gas companies. Energy Economics, 29 (3), 428-453.

Brown, P. A. S. and Yücel, M. K. (2002). Energy prices and aggregate economic activity: an interpretative survey. The Quarterly Review of Economics and Finance, 42, 193-208.

Campbell, J. Y., A. W. Lo, and A. C. MacKinlay (1997). The Econometrics of Financial Markets, Princeton University Press, Princeton, New Jersey. 
Chang, C.L., McAleer, M. and Tansuchat, R. (2012). Conditional correlations and volatility spillovers between crude oil and stock index returns. The North American Journal of Economics and Finance, in press.

Chen, S. S. (2009). Do higher oil prices push the stock market into bear territory?. Energy Economics, 32(2), 490-495.

Choi, K. and Hammoudeh, S. (2010). Volatility behavior of oil, industrial commodity and stock markets in a regime-switching environment. Energy Policy, 38, 4388-4399.

Cochrane, J. H. (2005). Asset Pricing, $2^{\text {nd }}$ edition, Princeton University Press, Princeton, New Jersey.

Cong, R. G., Wei, Y. M., Jiao, J. L. and Fan, Y. (2008). Relationships between oil price shocks and stock market: an empirical analysis from China. Energy Policy, 36, 3544-3553.

Driesprong, G., Jacobsen, B., and Maat, B. (2008). Striking oil: another puzzle?. Journal of Financial Economics, 89 (2), 307-327.

Elder, J. and Serletis, A. (2010). Oil Price Uncertainty. Journal of Money, Credit and Banking, 42 (6), 1137-1159.

El-Sharif, I., Brown, D., Burton, B., Nixon, B. and Russel, A. (2005). Evidence on the nature and extent of the relationship between oil and equity value in UK. Energy Economics, 27(6), 819-830.

Elyasiani, E., Mansur, I. and Odusami, B. (2011). Oil price shocks and industry stock returns. Energy Economics, 33, 966-74.

Engle, R.F. and Kroner, K.F. (1995). Multivariate Simultaneous Generalized ARCH. Econometric Theory, 11, 122-150.

Engle, R.F., Granger, C.W.J. and Kraft, D. (1986). Combining Competing Forecasts of Inflation Using a Bivariate ARCH Model. Journal of Economic Dynamics and Control, $8,151-165$.

EU Energy Policy Factsheet (2011). European Council Press, 4 February 2011.

Faff, R.W. and Brailsford, T.J. (1999). Oil price risk and the Australian stock market. Journal of Energy Finance and Development, 4, 69-87.

Ferson, W. W. and Harvey, C. R. (1994). Sources of risk and expected returns in global equity markets. Journal of Banking and Finance, 18, 775-803.

Ferson, W.W. and Harvey, C.R. (1995). Predictability and time-varying risk in world equity markets. Research in Finance, 13, 25-88. 
Filis, G. (2010). Macro economy, stock market and oil prices: Do meaningful relationships exist among their cyclical fluctuations? Energy Economics, 32(4), 877-886.

Filis, G., Degiannakis, S. and Floros, C. (2011). Dynamic correlation between stock market and oil prices: The case of oil-importing and oil-exporting countries. International Review of Financial Analysis, 20, 152-164.

Gjerde, $\varnothing$ and Sattem, F. (1999). Causal relations among stock returns and macroeconomic variables in a small, open economy. Journal of International Financial Markets, Institutions and Money, 9, 61-74.

Hacker, S.R. and Abdulnasser, H.-J. (2005). A Test for Multivariate ARCH Effects. Applied Economics Letters, 12(7), 411-417.

Hamilton, J.D. (1983). Oil and the macroeconomy since World War II. Journal of Political Economy, 91, 228-248.

Hamilton, J.D. (1988). Are the macroeconomic effects of oil-price changes symmetric? A comment. Carnegie-Rochester Conference Series on Public Policy, 28, 369-378.

Hamilton, J.D. (1996). This is what happened to the oil price-macroeconomy relationship. Journal of Monetary Economics, 38, 215-220.

Hamilton, J.D. (2008). Oil and the Macroeconomy. New Palgrave Dictionary of Economics, $2^{\text {nd }}$ edition, edited by Durlauf, S. and Blume, L., Palgrave McMillan Ltd.

Hamilton, J.D. (2009a). Causes and Consequences of the Oil Shock of 2007-08. Brookings Papers on Economic Activity, 1(Spring), 215-261.

Hamilton, J.D. (2009b). Understanding Crude Oil Prices. Energy Journal, 30, 179-206.

Hamilton, J. D. and Herrera, A. M. (2004). Oil Shocks and Aggregate Macroeconomic Behavior: The Role of Monetary Policy. Journal of Money, Credit, and Banking, 36(2), 265-86.

Hammoudeh, S. and Aleisa, E. (2004). Dynamic relationships among GCC stock markets and NYMEX oil futures. Contemporary Economic Policy, 22 (2), 250-269.

Hammoudeh, S. and Huimin, L. (2005). Oil sensitivity and systematic risk in oil-sensitive stock indices. Journal of Economics and Business, 57, 1-21.

Hammoudeh, S., Dibooglu, S. and Aleisa, E. (2004). Relationships among U.S. oil prices and oil industry equity indices. International Review of Economics and Finance, 13, $427-453$.

Hammoudeh, S. and Li, H. (2005). Oil sensitivity and systematic risk in oil-sensitive stock indices. Journal of Economics and Business, 57, 1-21. 
Henriques, I. and Sadorsky, P. (2008). Oil prices and the stock prices of alternative energy companies. Energy Economics, 30, 998-1010.

Hooker, A.M. (2002). Are oil shocks inflationary? Asymmetric and nonlinear specifications versus changes in regime. Journal of Money, Credit and Banking, 34 (2), 540-561.

Huang, R.D., Masulis, R.W. and Stoll, H.R. (1996). Energy shocks and financial markets. Journal of Futures Markets, 16, 1-27.

Huang, B.-N., Hwang, M.J. and Peng, H.-P. (2005). The asymmetry of the impact of oil price shocks on economic activities: an application of the multivariate threshold model. Energy Economics, 27, 445-476.

Iwayemi, A. and Fowowe B. (2011). Oil and the macroeconomy: empirical evidence from oil-exporting African countries. OPEC Energy Review, 35 (3), 227-269.

Jammazi, R. and Aloui, C. (2010). Wavelet decomposition and regime shifts: assessing the effects of crude oil shocks on stock market returns. Energy Policy, 38(3), 1415-1435.

Jbir, R. and Zouari-Ghorbel, S. (2009). Recent oil price shock and Tunisian economy. Energy Policy, 37, 1041-1051.

Jones, C.M. and Kaul, G. (1996). Oil and the stock markets. Journal of Finance, 51 (2), 463-491.

Jones, D.W., Lelby, P.N. and Paik, I.K. (2004). Oil prices shocks and the macroeconomy: what has been learned since. Energy Journal, 25, 1-32.

Kaneko, T. and Lee, B.S. (1995). Relative importance of economic factors in the U.S. and Japanese stock markets. Journal of the Japanese and International Economies, 9, 290307.

Kilian, L. (2008a). Exogenous oil supply shocks: how big are they and how much do they matter for the US economy? Review of Economics and Statistics, 90, 216-240.

Kilian, L. (2008b). The economic effects of energy price shocks. Journal of Economic Literature, 46, 871-909.

Kilian, L. (2009). Not all oil price shocks are alike: disentangling demand and supply shocks in the crude oil market. American Economic Review, 99 (3), 1053-1069.

Kilian, L. and Park, C. (2009). The impact of oil price shocks on the U.S. stock market. International Economic Review, 50(4), 1267-1287.

Kilian, L. and Lewis, L.T. (2011). Does the Fed Respond to Oil Price Shocks? Economic Journal, 121(555), 1047-1072.

Kim, I.M. and Loungani, P. (1992). The role of energy in real business cycle models. Journal of Monetary Economics, 29, 173-189. 
LeBlanc, M. and Chinn, D.M. (2004). Do high oil prices presage inflation? The evidence from G5 countries. Business Economics, 34, 38-48.

Lescaroux, F. and Mignon, V. (2009). The symposium on 'china's impact on the global economy': Measuring the effects of oil prices on china's economy: A factor-augmented vector autoregressive approach. Pacific Economic Review, 14 (3), 410-425.

Lippi, F. and Nobili, A. (2009). Oil and the macroeconomy: a quantitative structural analysis. Temi di discussione (Economic working papers) 704, Bank of Italy.

Lütkepohl, H. (1991). Introduction to Multiple Time Series Analysis, Springer Verlag, New York.

Lütkepohl, H. (2007). New Introduction to Multiple Time Series Analysis, Springer Verlag, New York.

Maghyereh, A. (2004). Oil price shocks and emerging stock markets. A generalized VAR approach. International Journal of Applied Econometrics and Quantitative Studies, 1, 27-40.

Miller, J. I. and Ratti, R.A. (2009). Crude oil and stock markets: Stability, instability, and bubbles. Energy Economics, 31, 559-568.

Mohanty, S. K., Nandha, M., Turkistani, A. Q. and Alaitani, M. Y. (2011). Oil price movements and stock market returns: Evidence from Gulf Cooperation Council (GCC) countries. Global Finance Journal, 22, 42-55.

Nandha, M. and Faff, R. (2008). Does oil move equity prices? A global view. Energy Economics, 30, 986-997.

Nandha, M. and Brooks, R. (2009). Oil prices and transport sector returns: an international analysis. Review of Quantitative Finance and Accounting, 33 (4), 393-409.

Narayan, P. K. and Sharma, S. S. (2011). New evidence on oil price and firm returns. Journal of Banking and Finance, 35 (12), 3253-3262.

Papapetrou, E. (2001). Oil price shocks, stock market, economic activity and employment in Greece. Energy Economics, 23, 511-532.

Park, J. and Ratti, R.A. (2008). Oil price shocks and stock markets in the US and 13 European countries. Energy Economics, 30, 2587-2608.

Rahman, S. and Serletis, A. (2010). The asymmetric effects of oil price and monetary policy shocks: A nonlinear VAR approach. Energy Economics, 32(6), 1460-1466.

Sadorsky, P. (1999). Oil price shocks and stock market activity. Energy Economics, 2, 449469. 
Sadorsky, P. (2001). Risk factors in stock returns of Canadian oil and gas companies. Energy Economics, 23, 17-28.

Sadorsky, P. (2012). Correlations and volatility spillovers between oil prices and the stock prices of clean energy and technology companies. Energy Economics, 34 (1), 248-255.

Scholtens, B. and Yurtsever, C. (2012). Oil price shocks and European industries. Energy Economics, in press.

Schwarz, G. (1978). Estimating the Dimension of a Model. Annals of Statistics, 6, 461-464.

Segal, P. (2011). Oil price shocks and the macroeconomy. Oxford Review of Economic Policy, 27 (1), 169-185.

Tang, W., Wu, L. and Zhang, Z.X. (2010). Oil price shocks and their short and long-term effects on the Chinese economy. Energy Economics, 32 (S1), S3-S14.

Tse, Y.K. (2002). Residual-based Diagnostics for Conditional Heteroscedasticity Models. Econometrics Journal, 5, 358-373.

Xekalaki, E. and Degiannakis, S. (2010). ARCH models for financial applications. Wiley and Sons, New York. 
Figures

Figure 1: Time-varying correlations, $\rho_{1, j, t}$, for the period 1992-2010.

CORREL FINANCIALS - OIL

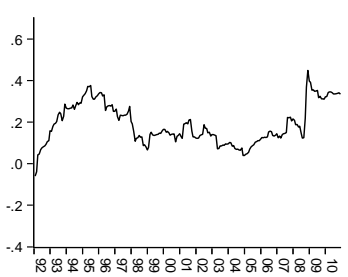

CORREL INDUSTRIALS - OIL

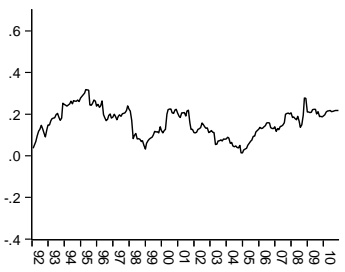

CORREL TELECOMMUNICATIONS - OIL

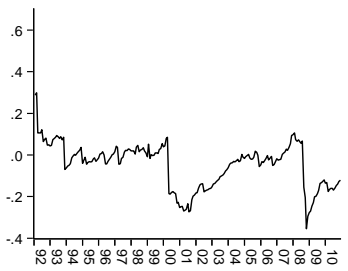

CORREL OIL\&GAS - OIL

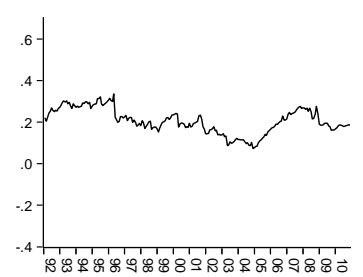

CORREL MATERIALS - OIL

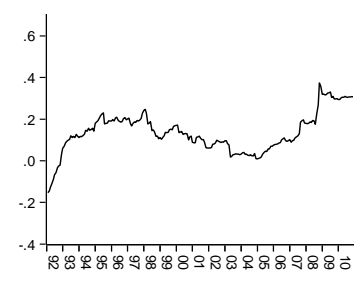

CORREL UTILITIES - OIL

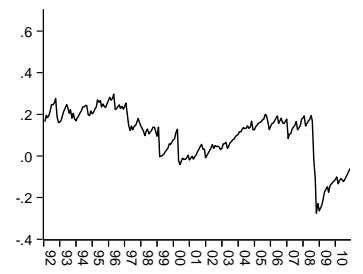

CORREL GOODS - OIL

CORREL HEALTH - OIL

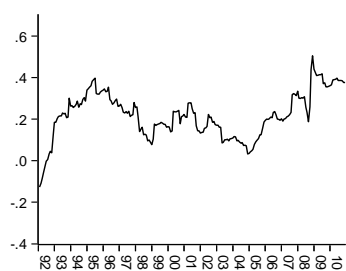

CORREL RETAIL - OIL

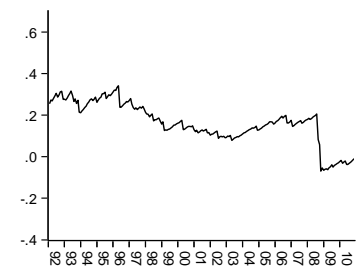

CORREL TECHNOLOGY - OIL
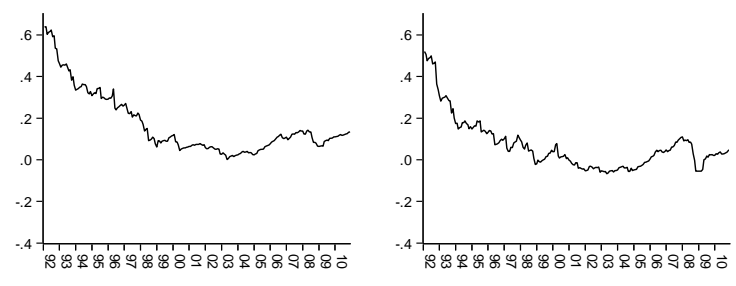
Figure 2: Time-varying correlations, $\rho_{1, j, t}$, for the period 1992-1996.

CORREL FINANCIALS - OIL

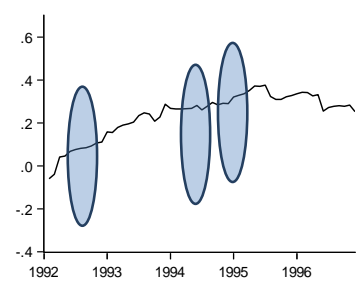

CORREL INDUSTRIALS - OIL

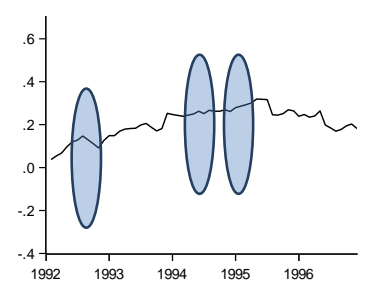

CORREL TELECOMMUNICATIONS - OIL

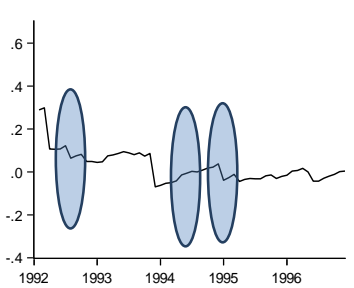

CORREL OIL\&GAS - OIL

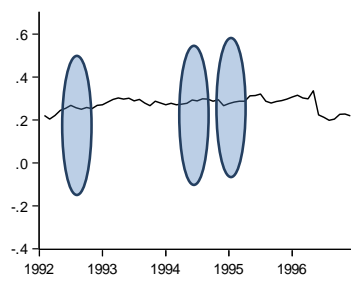

CORREL MATERIALS - OIL

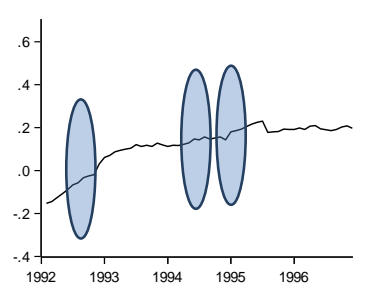

CORREL UTILITIES - OIL

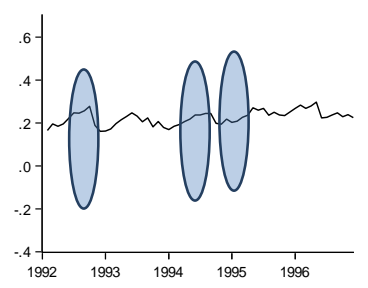

$\begin{array}{lllll}1992 & 1993 & 1994 & 1995 & 1996\end{array}$
CORREL HEALTH - OIL

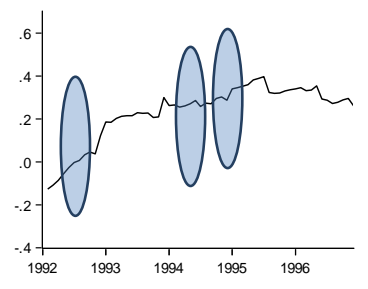

CORREL RETAIL - OIL

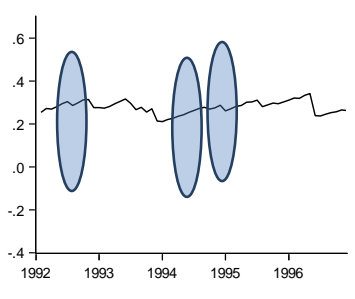

CORREL TECHNOLOGY - OIL
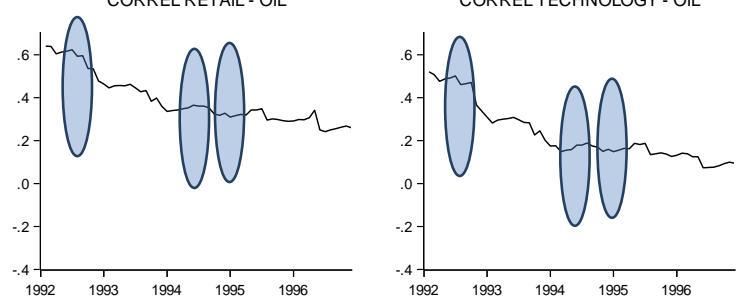
Figure 3: Time-varying correlations, $\rho_{1, j, t}$, for the period 1997-1999.
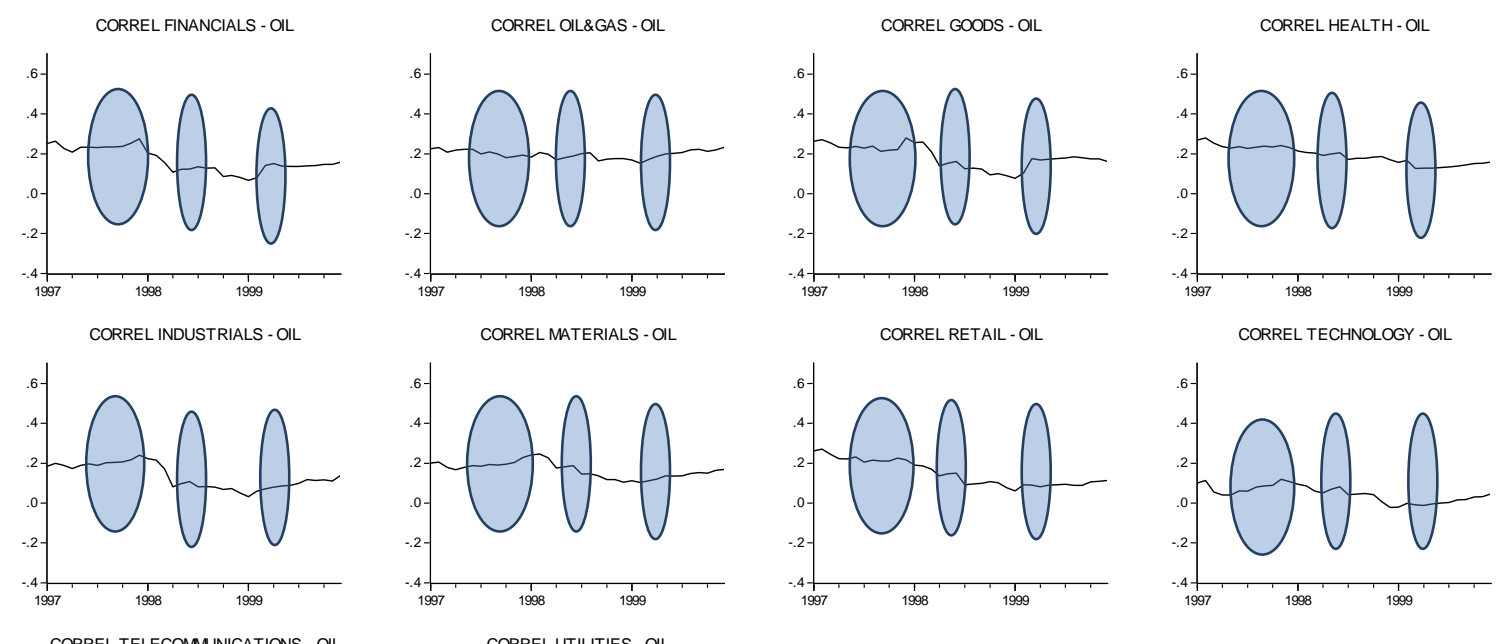

CORREL TELECOMMUNICATIONS - OIL

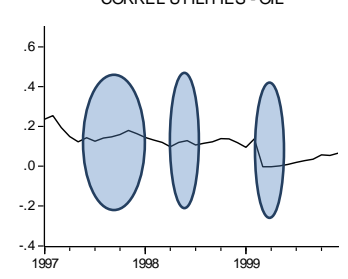


Figure 4: Time-varying correlations, $\rho_{1, j, t}$, for the period 2000-2003.
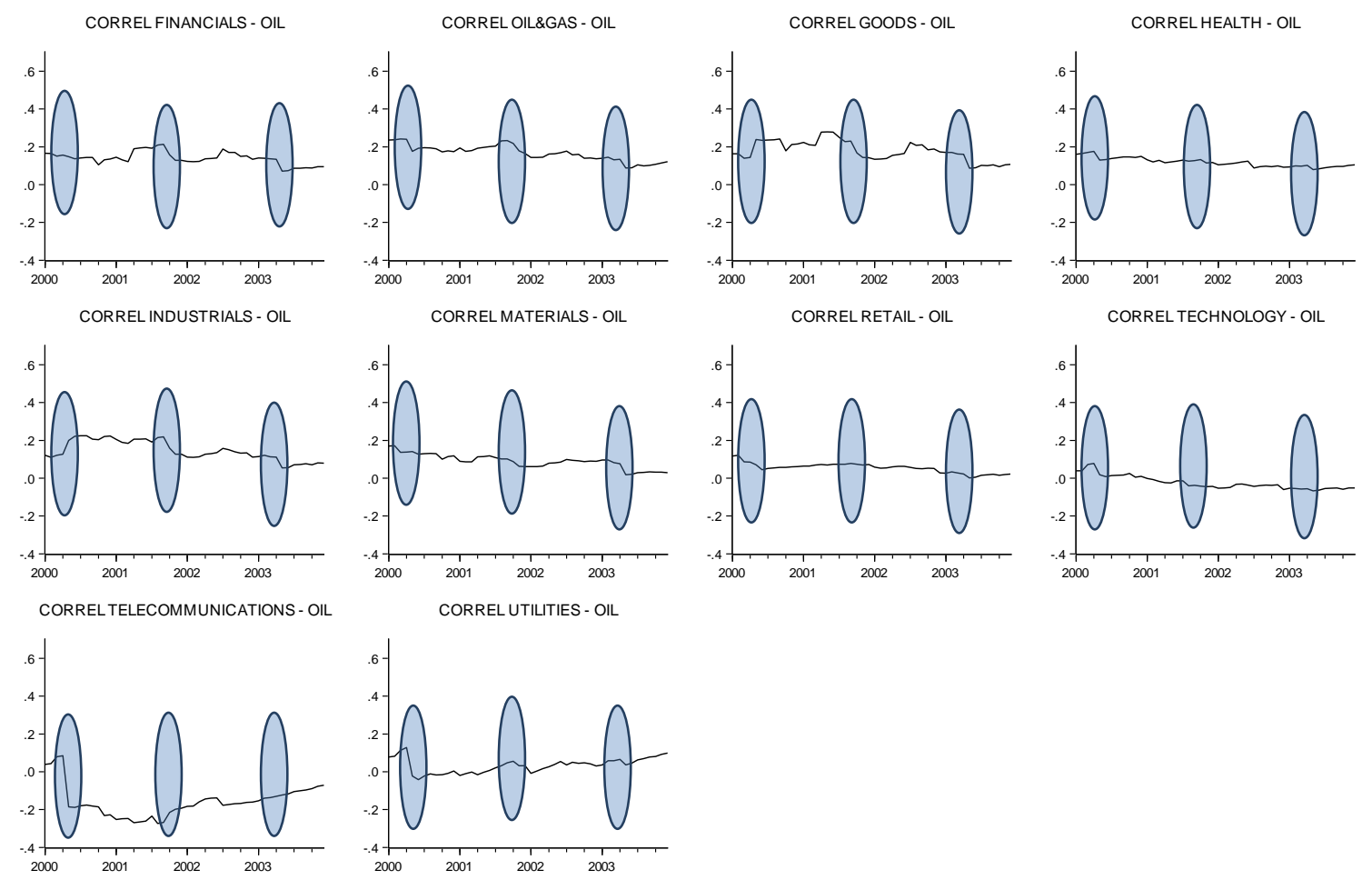
Figure 5: Time-varying correlations, $\rho_{1, j, t}$, for the period 2003-2007.
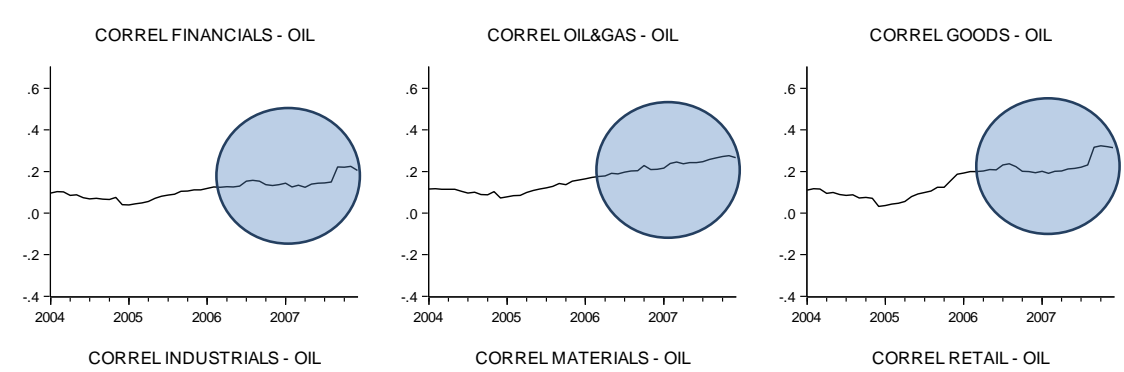

CORREL HEALTH - OIL
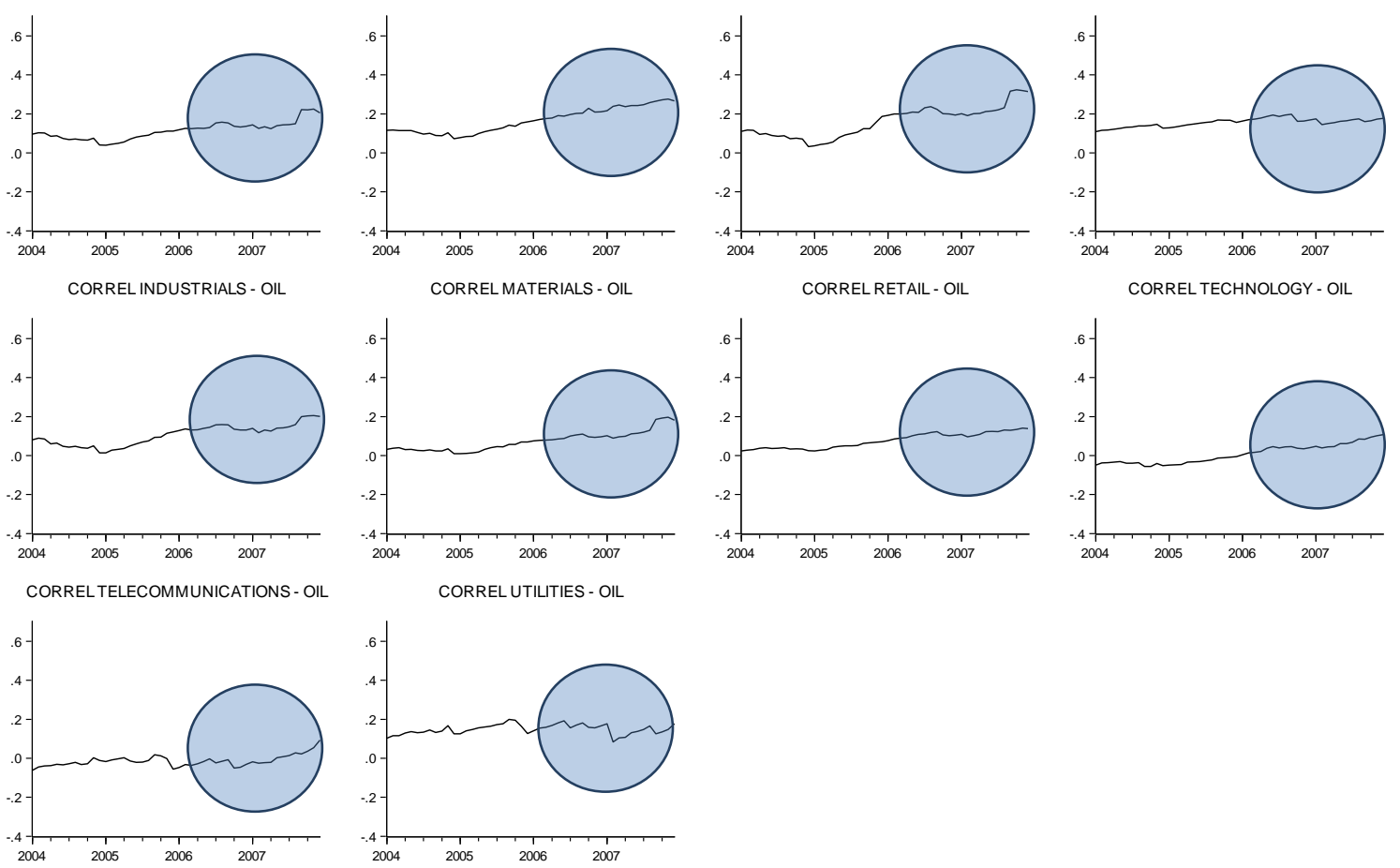
Figure 6: Time-varying correlations, $\rho_{1, j, t}$, for the period 2008-2010.
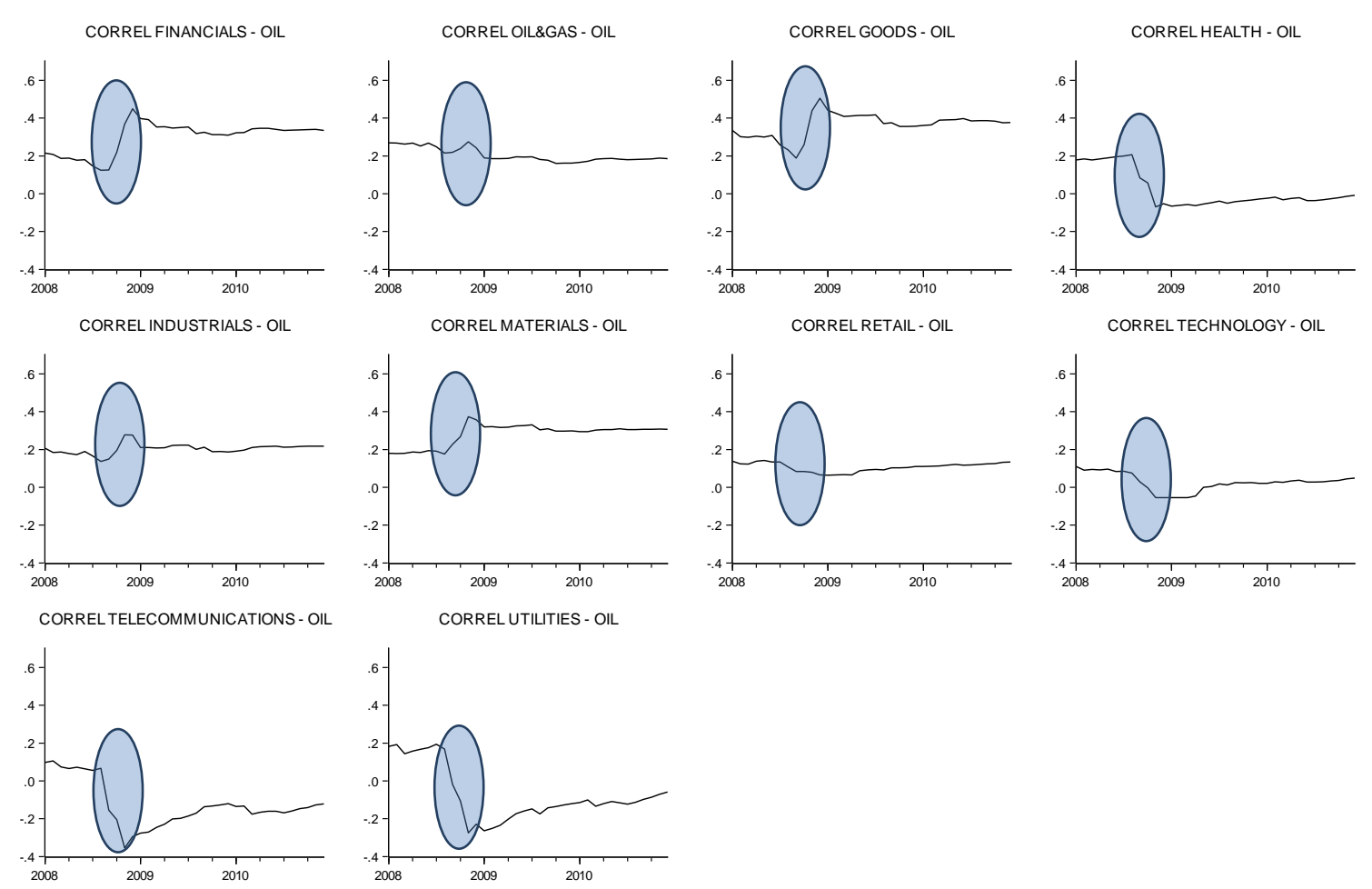


\section{Tables}

\begin{tabular}{lccccc}
\hline \multicolumn{5}{l}{ Table 1: Descriptive statistics of the time-varying correlations for the period 1992-2010. } \\
\cline { 2 - 6 } Mean & Financials & Oil\&Gas & Consumer Goods & Health & Industrials \\
\cline { 2 - 6 } Median & 0.1898 & 0.2055 & 0.2184 & 0.1635 & 0.1609 \\
Maximum & 0.1558 & 0.1995 & 0.2149 & 0.1644 & 0.1694 \\
Minimum & 0.4488 & 0.3363 & 0.5056 & 0.3416 & 0.3188 \\
Std. Dev. & -0.0595 & 0.0728 & -0.1270 & -0.0697 & 0.0138 \\
Skewness & 0.0969 & 0.0600 & 0.1102 & 0.0978 & 0.0687 \\
Kurtosis & 0.3789 & -0.0940 & -0.1861 & -0.5533 & -0.0681 \\
& 2.2719 & 2.3076 & 3.0909 & 2.9286 & 2.2404 \\
& & & & & \\
Mean & Materials & Retail & Technology & Telecommunications & Utilities \\
Median & 0.1353 & 0.1691 & 0.0678 & -0.0470 & 0.1028 \\
Maximum & 0.1204 & 0.1088 & 0.0383 & -0.0205 & 0.1360 \\
Minimum & 0.3747 & 0.6395 & 0.5202 & 0.2986 & 0.2966 \\
Std. Dev. & -0.1535 & 0.0012 & -0.0676 & -0.3540 & -0.2756 \\
Skewness & 0.0954 & 0.1492 & 0.1240 & 0.1054 & 0.1217 \\
Kurtosis & 0.0337 & 1.3755 & 1.7571 & -0.3704 & -0.9540 \\
& 3.3899 & 4.1798 & 6.2368 & 3.2089 & 3.4415 \\
\hline
\end{tabular}

Table 2: Descriptive statistics of the time-varying correlations for the period 1992-1996.

\begin{tabular}{lccccc} 
& Financials & Oil\&Gas & Consumer Goods & Health & Industrials \\
\cline { 2 - 6 } Mean & 0.2389 & 0.2737 & 0.2312 & 0.2781 & 0.2078 \\
Median & 0.2684 & 0.2796 & 0.2716 & 0.2782 & 0.2336 \\
Maximum & 0.3760 & 0.3363 & 0.3976 & 0.3416 & 0.3188 \\
Minimum & -0.0595 & 0.1986 & -0.1270 & 0.2117 & 0.0363 \\
Std. Dev. & 0.1038 & 0.0319 & 0.1323 & 0.0287 & 0.0679 \\
Skewness & -1.0759 & -0.7271 & -1.2908 & -0.2211 & -0.5618 \\
Kurtosis & 3.4270 & 2.8434 & 3.7133 & 2.7793 & 2.6549
\end{tabular}

\begin{tabular}{lccccc} 
& Materials & Retail & Technology & Telecommunications & Utilities \\
\cline { 2 - 5 } Mean & 0.1148 & 0.3874 & 0.2293 & 0.0252 & 0.2239 \\
Median & 0.1429 & 0.3477 & 0.1759 & 0.0037 & 0.2257 \\
Maximum & 0.2299 & 0.6395 & 0.5202 & 0.2986 & 0.2966 \\
Minimum & -0.1535 & 0.2407 & 0.0724 & -0.0695 & 0.1607 \\
Std. Dev. & 0.1017 & 0.1143 & 0.1302 & 0.0725 & 0.0328 \\
Skewness & -1.2668 & 0.9183 & 0.9957 & 1.6971 & -0.0471 \\
Kurtosis & 3.5914 & 2.7206 & 2.7854 & 7.0524 & 2.3551 \\
\hline
\end{tabular}




\begin{tabular}{lccccc}
\hline \multicolumn{5}{l}{ Table 3: Descriptive statistics of the time-varying correlations for the period 1997-1999. } \\
\cline { 2 - 6 } Mean & Financials & Oil\&Gas & Consumer Goods & Health & Industrials \\
\cline { 2 - 6 } Median & 0.1675 & 0.1979 & 0.1851 & 0.1922 & 0.1344 \\
Maximum & 0.1468 & 0.1995 & 0.1779 & 0.1893 & 0.1152 \\
Minimum & 0.2753 & 0.2335 & 0.2801 & 0.2797 & 0.2407 \\
Std. Dev. & 0.0666 & 0.1525 & 0.0774 & 0.1260 & 0.0317 \\
Skewness & 0.0596 & 0.0209 & 0.0566 & 0.0437 & 0.0607 \\
Kurtosis & 0.2056 & -0.1689 & -0.1611 & 0.1163 & 0.1670 \\
& 1.8304 & 2.1065 & 2.0332 & 1.9275 & 1.5607 \\
& & & & & \\
Mean & Materials & Retail & Technology & Telecommunications & Utilities \\
Median & 0.1664 & 0.1502 & 0.0459 & 0.0146 & 0.1112 \\
Maximum & 0.1683 & 0.1258 & 0.0456 & 0.0192 & 0.1226 \\
Minimum & 0.2466 & 0.2704 & 0.1191 & 0.0539 & 0.2538 \\
Std. Dev. & 0.1034 & 0.0616 & -0.0220 & -0.0452 & -0.0024 \\
Skewness & 0.0391 & 0.0638 & 0.0399 & 0.0228 & 0.0633 \\
Kurtosis & 0.1841 & 0.3694 & 0.0163 & -0.7159 & -0.1343 \\
\hline
\end{tabular}

Table 4: Descriptive statistics of the time-varying correlations for the period 2000-2003.

\begin{tabular}{lccccc} 
& Financials & Oil\&Gas & Consumer Goods & Health & Industrials \\
\cline { 2 - 6 } Mean & 0.1399 & 0.1670 & 0.1785 & 0.1180 & 0.1462 \\
Median & 0.1394 & 0.1711 & 0.1706 & 0.1161 & 0.1313 \\
Maximum & 0.2132 & 0.2417 & 0.2785 & 0.1758 & 0.2243 \\
Minimum & 0.0716 & 0.0877 & 0.0858 & 0.0791 & 0.0540 \\
Std. Dev. & 0.0343 & 0.0416 & 0.0531 & 0.0238 & 0.0526 \\
Skewness & 0.0658 & -0.0244 & 0.0508 & 0.5703 & 0.0782 \\
Kurtosis & 2.7554 & 2.3144 & 2.1046 & 2.6156 & 1.7790 \\
& & & & & \\
& Materials & Retail & Technology & Telecommunications & Utilities \\
\cline { 2 - 5 } Mean & 0.0896 & 0.0541 & -0.0239 & -0.1570 & 0.0335 \\
Median & 0.0902 & 0.0570 & -0.0371 & -0.1712 & 0.0358 \\
Maximum & 0.1723 & 0.1213 & 0.0775 & 0.0849 & 0.1279 \\
Minimum & 0.0181 & 0.0012 & -0.0676 & -0.2739 & -0.0423 \\
Std. Dev. & 0.0375 & 0.0259 & 0.0356 & 0.0853 & 0.0394 \\
Skewness & -0.0927 & 0.0847 & 1.1113 & 1.1781 & 0.2126 \\
Kurtosis & 2.6588 & 3.2104 & 3.5285 & 4.4493 & 2.4396 \\
\hline
\end{tabular}




\begin{tabular}{lccccc}
\hline \multicolumn{5}{l}{ Table 5: Descriptive statistics of the time-varying correlations for the period 2004-2007. } \\
\cline { 2 - 6 } Mean & Financials & Oil\&Gas & Consumer Goods & Health & Industrials \\
\cline { 2 - 6 } Median & 0.1143 & 0.1662 & 0.1593 & 0.1557 & 0.1052 \\
Maximum & 0.1153 & 0.1622 & 0.1887 & 0.1602 & 0.1196 \\
Minimum & 0.2246 & 0.2758 & 0.3234 & 0.1983 & 0.2049 \\
Std. Dev. & 0.0390 & 0.0728 & 0.0327 & 0.1091 & 0.0138 \\
Skewness & 0.0457 & 0.0635 & 0.0791 & 0.0220 & 0.0530 \\
Kurtosis & 0.5781 & 0.2157 & 0.2626 & -0.1600 & 0.0249 \\
& 3.2076 & 1.6511 & 2.2577 & 2.3548 & 2.0418 \\
& & & & & \\
Mean & Materials & Retail & Technology & Telecommunications & Utilities \\
Median & 0.0734 & 0.0765 & 0.0083 & -0.0136 & 0.1487 \\
Maximum & 0.0723 & 0.0742 & -0.0007 & -0.0183 & 0.1485 \\
Minimum & 0.1974 & 0.1411 & 0.1079 & 0.0935 & 0.1995 \\
Std. Dev. & 0.0092 & 0.0236 & -0.0566 & -0.0620 & 0.0832 \\
Skewness & 0.0491 & 0.0387 & 0.0484 & 0.0288 & 0.0258 \\
Kurtosis & 0.8433 & 0.0968 & 0.3517 & 1.2958 & -0.2020 \\
\hline
\end{tabular}

Table 6: Descriptive statistics of the time-varying correlations for the period 2008-2010.

\begin{tabular}{lccccc} 
& Financials & Oil\&Gas & Consumer Goods & Health & Industrials \\
\cline { 2 - 6 } Mean & 0.2989 & 0.2051 & 0.3631 & 0.0183 & 0.2042 \\
Median & 0.3350 & 0.1871 & 0.3761 & -0.0275 & 0.2098 \\
Maximum & 0.4488 & 0.2752 & 0.5056 & 0.2060 & 0.2783 \\
Minimum & 0.1239 & 0.1610 & 0.1884 & -0.0697 & 0.1368 \\
Std. Dev. & 0.0826 & 0.0365 & 0.0641 & 0.0974 & 0.0271 \\
Skewness & -0.7835 & 0.7882 & -0.6746 & 1.0952 & 0.3189 \\
Kurtosis & 2.5507 & 2.1058 & 3.6000 & 2.4319 & 4.9500 \\
& & & & & \\
& Materials & Retail & Technology & Telecommunications & Utilities \\
\cline { 2 - 5 } Mean & 0.2809 & 0.1068 & 0.0267 & -0.1249 & -0.0729 \\
Median & 0.3052 & 0.1112 & 0.0277 & -0.1505 & -0.1155 \\
Maximum & 0.3747 & 0.1417 & 0.1097 & 0.1063 & 0.1941 \\
Minimum & 0.1757 & 0.0645 & -0.0551 & -0.3540 & -0.2756 \\
Std. Dev. & 0.0572 & 0.0235 & 0.0465 & 0.1207 & 0.1445 \\
Skewness & -0.8607 & -0.4496 & -0.2446 & 0.6111 & 0.8119 \\
Kurtosis & 2.3966 & 2.0865 & 2.5326 & 2.5602 & 2.4246 \\
\hline
\end{tabular}

